\title{
Potential confounders for the effect of high-flow nasal cannula oxygen therapy
}

\author{
Satoshi Yamaga, Shinichiro Ohshimo* (10) and Nobuaki Shime \\ See related research by Di Mussi et al., https://ccforum.biomedcentral.com/articles/10.1186/s13054-018-2107-9
}

To the Editor:

We read with considerable interest the article published in a recent issue of Critical Care by Di Mussi and colleagues [1], who investigated the physiological effects of high-flow nasal canula (HFNC) compared with conventional $\mathrm{O}_{2}$ therapy after extubation in patients with chronic obstructive pulmonary disease (COPD) receiving mechanical ventilation. The authors demonstrated that postextubation HFNC significantly decreased neuroventilatory drive and the work of breathing compared with conventional $\mathrm{O}_{2}$ therapy. However, several factors that might potentially affect their results should be discussed.

First, although the authors discussed one of the mechanisms related to the decreased work of breathing using HFNC compared with conventional $\mathrm{O}_{2}$ therapy, which was associated with the flow-dependent $\mathrm{CO}_{2}$ wash-out effect, they did not directly assess the relationship between the variables of work of breathing and the flow rate of HFNC. Various flow rates ranging from 20 to $60 \mathrm{~L} / \mathrm{min}$ were used in this study, which are inconsistent with previous studies, where the flow rates of HFNC were fixed [2,3]. A higher flow rate of HFNC potentially increases the $\mathrm{CO}_{2}$ wash-out effect and consequently decreases the respiratory effort [4].

Second, the reasons for reintubation in this study were unclear. The authors failed to show a correlation between the work of breathing and the requirement of reintubation; more significant risk factors of reintubation could include other clinical conditions. Shock or disturbed consciousness, masking the effect of HFNC, might be potential confounders in this study.

Finally, we would like to know the differences in clinical characteristics between the patients who benefited from HFNC and those who did not. The authors demonstrated that several patients showed almost no change in neuroventilatory drive and work of breathing

\footnotetext{
* Correspondence: ohshimos@hiroshima-u.ac.jp

Department of Emergency and Critical Care Medicine, Graduate School of Biomedical \& Health Sciences, Hiroshima University, 1-2-3 Kasumi, Minami-ku, Hiroshima 734-8551, Japan
}

(c) The Author(s). 2019 Open Access This article is distributed under the terms of the Creative Commons Attribution 4.0 International License (http://creativecommons.org/licenses/by/4.0/), which permits unrestricted use, distribution, and reproduction in any medium, provided you give appropriate credit to the original author(s) and the source, provide a link to the Creative Commons license, and indicate if changes were made. The Creative Commons Public Domain Dedication waiver (http://creativecommons.org/publicdomain/zero/1.0/) applies to the data made available in this article, unless otherwise stated. independent of the use of HFNC or conventional $\mathrm{O}_{2}$ therapy. We speculate that the strength of respiratory drive or the severity of COPD affected these parameters.

In conclusion, we believe that clarification of these issues by the authors would be helpful for a better understanding of the benefit of postextubation HFNC in patients with COPD.

\section{Abbreviations}

COPD: Chronic obstructive pulmonary disease; HFNC: High-flow nasal canula

\section{Acknowledgements}

We thank Edanz Group (www.edanzediting.com/ac) for editing a draft of this

\section{Funding}

This work was supported by KAKENHI Grants from the Japan Society for the Promotion of Science (JSPS) (numbers JP 16K09541, 17K11573 and 18K16540), and by the Strategic Information and Communications R\&D Promotion Programme (SCOPE), and the Japan Agency for Medical Research and Development (AMED)

\section{Availability of data and materials} Not applicable

\section{Authors' contributions \\ SY drafted the manuscript. SO and NS revised the manuscript. All authors read and approved the final manuscript.}

Ethics approval and consent to participate Not applicable

Consent for publication

Not applicable

\section{Competing interests}

The authors declare that they have no competing interests.

\section{Publisher's Note}

Springer Nature remains neutral with regard to jurisdictional claims in published maps and institutional affiliations.

Received: 5 December 2018 Accepted: 3 January 2019

Published online: 17 January 2019

\section{References}

1. Di Mussi R, Spadaro S, Stripoli T, Volta CA, Trerotoli P, Pierucci P, Staffieri F, Bruno F, Camporota L, Grasso S. High-flow nasal cannula oxygen therapy manuscript. 
decreases postextubation neuroventilatory drive and work of breathing in patients with chronic obstructive pulmonary disease. Crit Care. 2018;22:180.

2. Maggiore SM, Idone FA, Vaschetto R, Festa R, Cataldo A, Antonicelli F, Montini L, De Gaetano A, Navalesi P, Antonelli M. Nasal high-flow versus Venturi mask oxygen therapy after extubation. Effects on oxygenation, comfort, and clinical outcome. Am J Respir Crit Care Med. 2014;190:282-8.

3. Rittayamai N, Tscheikuna J, Rujiwit P. High-flow nasal cannula versus conventional oxygen therapy after endotracheal extubation: a randomized crossover physiologic study. Respir Care. 2014;59:485-90.

4. Mauri T, Alban L, Turrini C, Cambiaghi B, Carlesso E, Taccone P, Bottino N, Lissoni A, Spadaro S, Volta CA, Gattinoni L, Pesenti A, Grasselli G. Optimum support by high-flow nasal cannula in acute hypoxemic respiratory failure: effects of increasing flow rates. Intensive Care Med. 2017;43:1453-63. 